\title{
Prevalence and patterns of multimorbidity in Australian baby boomers: the Busselton healthy ageing study
}

Michael L. Hunter ${ }^{1,2,3^{*}}$ (D), Matthew W. Knuiman ${ }^{2}$ D, Bill (A.W.) Musk ${ }^{1,2} \mathbb{D}$, Jennie Hui ${ }^{1,2,4} \mathbb{D}$, Kevin Murray ${ }^{2}$ (D) John P. Beilby ${ }^{1,4} \mathbb{D}$, David R. Hillman ${ }^{5}$ (D) Joseph Hung ${ }^{1,6}$ (D), Robert U. Newton ${ }^{7}$ (D), Romola S. Bucks ${ }^{8}$ (D)

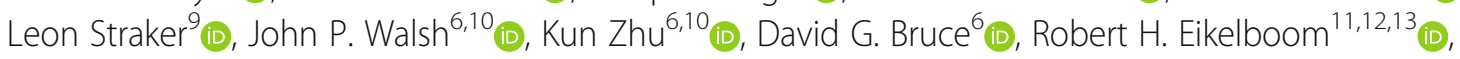
Timothy M. E. Davis ${ }^{14}$ (D) David A. Mackey ${ }^{15}$ (D) and Alan L. James ${ }^{1,5}$ (D)

\begin{abstract}
Background and objective: Chronic medical conditions accumulate within individuals with age. However, knowledge concerning the trends, patterns and determinants of multimorbidity remains limited. This study assessed the prevalence and patterns of multimorbidity using extensive individual phenotyping in a general population of Australian middle-aged adults.

Methods: Participants ( $n=5029,55 \%$ female), born between 1946 and 1964 and attending the cross-sectional phase of the Busselton Healthy Ageing Study (BHAS) between 2010 and 2015, were studied. Prevalence of 21 chronic conditions was estimated using clinical measurement, validated instrument scores and/or self-reported doctor-diagnosis. Non-random patterns of multimorbidity were explored using observed/expected (O/E) prevalence ratios and latent class analysis (LCA). Variables associated with numbers of conditions and class of multimorbidity were investigated.
\end{abstract}

Results: The individual prevalence of 21 chronic conditions ranged from 2 to $54 \%$ and multimorbidity was common with $73 \%$ of the cohort having 2 or more chronic conditions. (mean \pm SD $2.75 \pm 1.84$, median $=2.00$, range $0-13$ ). The prevalence of multimorbidity increased with age, obesity, physical inactivity, tobacco smoking and family history of asthma, diabetes, myocardial infarct or cancer. There were 13 pairs and 27 triplets of conditions identified with a prevalence $>1.5 \%$ and $\mathrm{O} / \mathrm{E}>1.5$. Of the triplets, arthritis $(>50 \%)$, bowel disease $(>33 \%)$ and depressionanxiety (> 33\%) were observed most commonly. LCA modelling identified 4 statistically and clinically distinct classes of multimorbidity labelled as: 1) "Healthy" (70\%) with average of 1.95 conditions; 2) "Respiratory and Atopy" (11\%, 3.65 conditions); 3) "Non-cardiometabolic" (14\%, 4.77 conditions), and 4) "Cardiometabolic" (5\%, 6.32 conditions). Predictors of multimorbidity class membership differed between classes and differed from predictors of number of co-occurring conditions.

\footnotetext{
* Correspondence: michael.hunter@uwa.edu.au

'Busselton Population Medical Research Institute Inc, Nedlands, WA 6009, Australia

${ }^{2}$ School of Population and Global Health, The University of Western Australia, Crawley, WA 6009, Australia

Full list of author information is available at the end of the article
}

(C) The Author(s). 2021 Open Access This article is licensed under a Creative Commons Attribution 4.0 International License, which permits use, sharing, adaptation, distribution and reproduction in any medium or format, as long as you give appropriate credit to the original author(s) and the source, provide a link to the Creative Commons licence, and indicate if changes were made. The images or other third party material in this article are included in the article's Creative Commons. licence, unless indicated otherwise in a credit line to the material. If material is not included in the article's Creative Commons licence and your intended use is not permitted by statutory regulation or exceeds the permitted use, you will need to obtain permission directly from the copyright holder. To view a copy of this licence, visit http://creativecommons.org/licenses/by/4.0/. The Creative Commons Public Domain Dedication waiver (http://creativecommons.org/publicdomain/zero/1.0/) applies to the data made available in this article, unless otherwise stated in a credit line to the data. 
Conclusion: Multimorbidity is common among middle-aged adults from a general population. Some conditions associated with ageing such as arthritis, bowel disease and depression-anxiety co-occur in clinically distinct patterns and at higher prevalence than expected by chance. These findings may inform further studies into shared biological and environmental causes of co-occurring conditions of ageing. Recognition of distinct patterns of multimorbidity may aid in a holistic approach to care management in individuals presenting with multiple chronic conditions, while also guiding health resource allocation in ageing populations.

Keywords: Multimorbidity, Ageing, Co-morbidities, Middle-aged, Chronic disease

\section{Background}

In Australia and other developed countries, increasing life expectancy and the transition of the Baby Boomer generation (adults born 1946 to 1964) from middle into older age has led to an increasing number of people with multimorbidity, commonly defined as the presence of two or more chronic, long-term health conditions [1]. Most studies report that multimorbidity is the norm in the elderly and common in middle-age (45-64 years) [1$3]$. Multimorbidity is associated with greater risk of mortality, poor quality of life, psychological stress, cognitive decline, impaired functional capacity, greater use of health and social support services and reduced work productivity [3-10]. The growing prevalence of multimorbidity is also recognised in low- to middle income countries where additional factors such as the presence of communicable diseases, demographic transition and socio-economic challenges contribute to the complexity and burden of multimorbidity in these settings [11].

Individuals with multimorbidity have complex healthcare needs that may not be adequately addressed by models of health care centred on managing and treating single conditions. They are also at increased risk of adverse drug effects from polypharmacy and potential harm from conflicting treatment or lifestyle recommendations [12]. Despite attempts to address these complex needs in clinical guidelines [2, 13-15], knowledge concerning the trends, patterns and determinants of multimorbidity remains sub-optimal. This has significant implications for future healthcare service planning and allocation of resources.

There have been several studies of the prevalence of multimorbidity in primary care and general populations including in Australia over the last decade [16]. These have mostly involved cohorts, aged $>65+$ years and have used clinical administrative data, self-report or national survey datasets to identify conditions and a variety of measures to define multimorbidity [16-23]. The measures of multimorbidity in these studies are constrained by the available data and vary widely in terms of the number of considered conditions and their definitions [24]. As a result, the prevalence and patterns of multimorbidity derived from different data sources are often inconsistent, even when generated from the same population sample $[25,26]$. Notably, there have been few community-based studies of multimorbidity, particularly in middle-aged adults, that have used clinically-defined, objective measures of chronic disease [14]. In their review Fortin et al. concluded that, in general, multimorbidity increases with age, especially from the age of 40 years with a plateau around 70 years, if $\geq 2$ conditions are used to define multimorbidity [14]. This plateau was less evident if $\geq 3$ conditions was used to define multimorbidity.

Certain conditions may be more likely to cluster than others [27]. This may be the consequence of shared pathophysiological pathways, in which the presence of one condition increases the risk of another, or may reflect common environmental or biological risk factors. In order to better understand the factors underlying patterns of comorbidity and to thus inform healthcare planning, there have been recent calls for studies in general population samples, assessing a wide range of conditions characterised by objective clinical data including information on symptoms, lifestyle behaviours and environmental risk factors [28]. General population samples matching these requirements, particularly in middle-age when intervention for chronic conditions is likely to have greatest impact in older age, are few.

The Busselton Healthy Ageing Study (BHAS) is one such study where detailed measures of physical function, cognition, well-being, quality of life, medical history and biological samples have been collected enabling investigation into specific interactions between disease processes and symptoms within individuals [29]. The objective of this analysis was to investigate the prevalence and patterns of multimorbidity using a range of measures of chronic disease collected in the BHAS dataset. We hypothesised that co-occurring conditions are common in middle-aged adults, that there are identifiable non-random patterns of multimorbidity and that these patterns are associated with distinct risk factors and/or explanatory variables.

\section{Methods}

\section{Population study sample}

A comprehensive, community-based health survey of adults born 1946-1964 residing within the City of 
Busselton's local government electoral boundary in Western Australia was undertaken from May 2010 to December 2015. All people listed on the compulsory Western Australian Electoral Commission Electoral Roll were invited to participate. Recruitment was via postal invitation and by telephone where a contact number was available. A total of $82 \%$ of those on the electoral register could be contacted and confirmed eligible (non-institutionalised and still living in the region) and 76\% of those contacted (5107) participated in the study. Ethical approval for this study was obtained from the Human Research Ethics Committee of the University of Western Australia (RA/4/1/2203). All study participants provided written informed consent.

Participants completed a detailed questionnaire that included items relating to medical and family history, symptoms, physical activity and diet and nutrition (see Supplementary File 1). They attended the survey centre for up to $4 \mathrm{~h}$ of clinical assessments, which included: spirometry, skin prick (atopy), audiometry, cardiovascular profiling (Ankle-Brachial Index, ABI) and electrocardiogram (ECG), bone densitometry and an in-home overnight Apnealink $^{\mathrm{TM}}$ sleep study. Participants also provided a fasting blood sample for blood glucose, haemoglobin and white cell count, glycated haemoglobin (HbA1c) and estimated glomerular filtration rate [30]. All clinical tests were conducted by accredited pathology laboratories (PathWest, Busselton \& Nedlands, Western Australia). The complete BHAS protocol has been described in detail previously [29].

Based on the participants' responses and testing, 21 conditions were defined and included in this analysis (Table 1). Six conditions were defined using only objective measures or validated instrument scale score [3134]. Seven conditions were defined using a combination of objective measures or validated instrument plus selfreported doctor diagnosis and eight conditions were defined only by self-reported doctor diagnosis which was a "Yes" response to the question, "Has a Doctor ever diagnosed you with...?". The list of conditions used in this analysis ensured that the condition was prevalent and chronic using the best available data from questionnaire responses or clinical assessment.

\section{Prevalence estimates and patterns of multimorbidity}

The observed prevalence of each possible pair and triplet combinations of concurrent conditions was determined in the BHAS cohort. Pairs and triplets of conditions that occurred more often than expected by chance (determined by a chi-square test for statistical independence between conditions) were identified and the observed/ expected $(\mathrm{O} / \mathrm{E})$ prevalence ratio presented $[18,35]$. The expected chance prevalence under independence is calculated as the product of the observed prevalences of each condition in the pair or triplet.

Latent Class Analysis (LCA) was used to identify groups (latent classes) of individuals with similar disease profiles, that is, similar patterns of multi-morbidity. LCA is a model-based statistical technique that is increasingly recommended and used for this purpose [18, 21, 36]. In our study the four class model was judged optimal and we present the proportion of the population that is estimated to be in each class, the estimated probabilities that a person in each class has each of the 21 conditions and the mean number of conditions for each class. The multimorbidity profile of each class was used to interpret and name the classes. Further details of the LCA analysis are provided in Supplementary File 2.

Multivariable logistic and linear regression modelling were used to identify the participant characteristics that were related to latent class membership and overall number of conditions respectively. Regression results are presented as estimates with $p$-values. Statistical analyses were performed using $\mathrm{SAS}^{\bullet}$ version 9.3 (and including the Proc LCA extension).

\section{Results}

Complete data on 21 chronic conditions were available for 5029 participants. The average age of the participants was 54 years (range 45-69 years); 55\% were female and 98\% were Caucasian. Demographic details of the cohort are provided in Supplementary Table S1. Comparison with the Australian National Health Survey 2011 for common risk factors for disease showed that the cohort was similar to the Australian population on a number of key health indicators including prevalence of obesity, hypertension, hypercholesterolemia, and physical activity rates. The prevalence of current tobacco smoking was $10 \%$ in the BHAS cohort, lower than the national average for this age group (15\%).

\section{Prevalence of individual conditions and number of conditions per person}

The prevalence and definitions of individual chronic conditions are shown in Table 1 . The number of co-occurring conditions ranged from 0 to 13 (mean 2.75, $\mathrm{SD}=1.84$ ), with $73 \%$ of participants having 2 or more conditions, $44 \%$ of participants having one or two conditions and $49 \%$ having three or more conditions. Only $7 \%$ of the cohort had no conditions. The mean and number of conditions increased with age, lower income and lower education level in both men and women (Supplementary Table S1).

\section{Relationship between number of conditions and participant characteristics}

Multiple linear regression modelling showed that female gender; older age; increased waist circumference; 
Table 1 Ranked prevalence of the 21 chronic conditions, with definitions, in 5029 Baby Boomers from the Busselton Healthy Ageing Study

\begin{tabular}{|c|c|c|}
\hline Condition & Definition & $\begin{array}{l}\text { Prevalence } \\
(\%)\end{array}$ \\
\hline Atopy & Positive (wheal > $3 \mathrm{~mm}$ ) on skin prick tests for common allergens (dust-mites, grasses, moulds, cat hair, dog dander) & 54.4 \\
\hline Arthritis & Self-reported doctor-diagnosed & 25.1 \\
\hline Bowel disease & Self-reported doctor-diagnosed colonic polyps, Crohn's disease, ulcerative colitis, irritable bowel syndrome or diverticular disease & 23.3 \\
\hline Liver disease & Self-reported doctor-diagnosed cirrhosis of the liver or ALT $>40 \mathrm{U} / \mathrm{L}$ in men or $>35 \mathrm{U} / \mathrm{L}$ in women & 23.1 \\
\hline Depression/anxiety & Current treatment or PHQ9 or GAD7 scores indicative of current depression or anxiety, respectively & 20.5 \\
\hline Bronchitis & Self-reported chronic cough or phlegm on most days for $>3$ months each year & 17.6 \\
\hline Eye condition & Self-reported macular degeneration, glaucoma, cataract, non-diabetes related serious eye condition resulting in loss of vision & 14.6 \\
\hline Asthma & Self-reported doctor-diagnosed asthma & 14.2 \\
\hline Heart disease & $\begin{array}{l}\text { Self-reported doctor-diagnosed angina, cardiac pacemaker, myocardial infarction, coronary angioplasty or stent, or bypass surgery } \\
\text { or Abnormal ECG }\end{array}$ & 9.7 \\
\hline Thyroid disease & Self-reported doctor-diagnosed & 8.6 \\
\hline Low back pain & Current self-reported chronic low back pain lasting $\geq 3$ months and Oswestry Disability Index $\geq 12$ & 8.5 \\
\hline Skin cancer & Self-reported doctor-diagnosed & 8.2 \\
\hline $\begin{array}{l}\text { Obstructive Sleep } \\
\text { Apnoea }\end{array}$ & Apnoea hypopnea index $>19 \wedge$ or, if not available, self-reported doctor-diagnosed & 8.1 \\
\hline Hearing impairment & Audiometry best ear 4-frequency average $>25 \mathrm{~dB}^{*}$ or, if not available, hearing impairment affecting daily life frequently/constantly & 7.1 \\
\hline Diabetes & $\begin{array}{l}\text { Self-reported doctor-diagnosed diabetes (not only during pregnancy) or fasting blood glucose }>7.0 \mathrm{mmol} / \mathrm{L} \text { or glycosylated hae- } \\
\text { maglobin }(\mathrm{HbA} 1 \mathrm{c})>6.5 \%\end{array}$ & 7 \\
\hline $\begin{array}{l}\text { Cancer (non-skin } \\
\text { cancer) }\end{array}$ & Self-reported doctor-diagnosed & 6.7 \\
\hline COPD & $\begin{array}{l}\text { Post-bronchodilator FEV1/FVC }<0.7 \text { and FEV1\% predicted }<80 \% \text { or, if spirometry not available, self-reported doctor-diagnosed } \\
\text { COPD }\end{array}$ & 5.7 \\
\hline Kidney disease & Self-reported doctor-diagnosed kidney disease or estimated glomerular filtration rate $<60 \mathrm{ml} / \mathrm{min}$ & 5.2 \\
\hline Osteoporosis & DXA measured femur or AP spine T-score $\leq-2.5 \wedge \wedge$ or, if not available, self-reported doctor-diagnosed & 3.4 \\
\hline Stroke & Self-reported doctor-diagnosed stroke, TIA or carotid surgery (endarterectomy or stent) & 2.1 \\
\hline $\begin{array}{l}\text { Peripheral artery } \\
\text { disease }\end{array}$ & Ankle brachial index $<0.9$ for right or left side $\wedge \wedge \wedge$ & 1.9 \\
\hline
\end{tabular}

tobacco smoking; reduced physical activity; and family history of asthma, diabetes, myocardial infarct and cancer were independently associated with increased number of chronic conditions (Supplementary Table S2). When standard drinks of alcohol per week and the dietary variables of meat meals per week, fish meals per week, vegetable serves per day, fruit serves per day, were added to the model they did not reach statistical significance $(p=$ 0.28 for alcohol and $p>0.05$ for dietary variables) and so were not included in the final presented model.

\section{Common pairs of conditions}

There was a total of $(21 \times 20) / 2=210$ possible pairs of conditions and all were observed with a prevalence that varied from 0.02 to $13.42 \%$ (Table 2). There were 13 pairs of conditions with observed prevalence $>1.5 \%$ and an $\mathrm{O} /$ E ratio $>1.5(p<0.0001$ for all) (Table 2). Arthritis and bowel disease was the most prevalent pair. Arthritis, low back pain and depression-anxiety each featured in at least three of these 13 pairs of conditions.

\section{Common triplets of conditions}

There was a total of $(21 \times 20 \times 19) / 6=1330$ possible triplets of conditions and 1261 were observed with prevalence from 0.02 to $4.97 \%$. There were 27 triplets with a prevalence $>1.5 \%$ and $\mathrm{O} / \mathrm{E}$ ratio $>1.5(\mathrm{p}<0.0001$ for all $)$ (Supplementary Table S3). Bowel disease, arthritis and atopy was the most prevalent triplet. Arthritis featured in 16 of these 27 triplets of conditions and bowel disease and depression-anxiety each featured in 11.

Patterns of multimorbidity - latent class analysis (LCA) The morbidity patterns for the 4-class model are shown in Table 3. The classes were defined as follows: Class 1 (70\% of participants) "healthy" - below average prevalence for 20/21 conditions and average of 1.95 conditions; Class 2 (11\%) "respiratory and atopy" - well above 
Table 2 All pairs of conditions with prevalence $>1.5 \%$ and observed/expected ratio $>1.5$ (and $p<0.0001$ )

\begin{tabular}{lllll}
\hline Co-occurring pairs of conditions & Prevalence (\%) & O/E \\
\hline Asthma & + & COPD & 2.41 & 2.95 \\
Depression-anxiety & + & Low back pain & 3.86 & 2.21 \\
Arthritis & + & Low back pain & 4.71 & 2.2 \\
Bronchitis & + COPD & 1.89 & 1.86 \\
Low back pain & + Bronchitis & 2.66 & 1.78 \\
Diabetes & + & Eye condition & 1.73 & 1.7 \\
Diabetes & + & Liver disease & 2.66 & 1.66 \\
Depression-anxiety & + OSA & 2.64 & 1.6 \\
Thyroid disease & + & Arthritis & 3.46 & 1.59 \\
Kidney disease & + & Depression anxiety & 1.67 & 1.57 \\
Liver disease & + & OSA & 2.86 & 1.54 \\
Bowel disease & + & Low back pain & 3.02 & 1.53 \\
Bowel disease & + & Arthritis & 8.81 & 1.51 \\
\hline
\end{tabular}

Note. Total prevalence of co-occurring conditions was $73 \%$

average prevalence of asthma, COPD and atopy and below average prevalence of most other conditions, with an overall average of 3.65 conditions; Class 3 (14\%) "multimorbid non-cardiometabolic"- well above average prevalence of thyroid disease, bowel disease, osteoporosis, arthritis, low back pain, asthma, COPD, peripheral arterial disease, hearing impairment, bronchitis and eye conditions, with an overall average of 4.17 conditions; Class 4 (5\%) "multimorbid cardio-metabolic and other"well above average prevalence of heart disease, stroke, peripheral arterial disease, diabetes, kidney disease, liver disease, bowel disease, depression-anxiety, arthritis, low back pain, sleep apnoea, asthma, bronchitis, chronic hearing impairment and eye conditions, with an overall average of 6.32 conditions.

Arthritis, low back pain, bowel disease, depressionanxiety and bronchitis feature prominently in common pairs and triplets of conditions that occur much more often than expected by chance (all triplets $\mathrm{O} / \mathrm{E}>3.9$ ) and all of these conditions have high prevalence in multi-morbid classes 3 and 4.

Asthma, COPD and atopy is a common triplet that also occurs much more often than expected by chance $(\mathrm{O} / \mathrm{E}=3.95)$ and these three conditions have high prevalence in "respiratory and atopy" class 2.

\section{Characteristics of multimorbidity}

\section{Morbidity patterns versus number of conditions}

There was a very strong association between having $0-2$ conditions and being in 'healthy' class 1 (Supplementary Table S4). Of the people with $0-2$ conditions, $95 \%$ were assigned to 'healthy' class 1 and $69 \%$ of people in class 1 had 0-2 conditions. Therefore, correlates and predictors of being in 'healthy' class 1 and having $0-2$ conditions are essentially the same. People with 3-6 conditions make up $46 \%$ of the total sample and were distributed across all four classes. Although there was a strong association between having $7+$ conditions and being in unhealthy class 3 or 4 ( $94 \%$ of people with $7-13$ conditions were assigned to unhealthy classes 3 and 4), the morbidity pattern was different for class 3 and class 4 . Thus, amongst people with three or more conditions, the number of conditions alone was not sufficient to discern the pattern of multi-morbidity and correlates. Therefore predictors of being in class 3 and 4 may be quite different and will not necessarily be the same as correlates of the overall number of conditions.

\section{Characteristics across assigned multimorbidity classes}

Participants in the multi-morbid classes 3 and 4 were, on average, 3 years older than those in classes 1 and 2 (Table 4). Classes 1 and 2 had approximately equal numbers of men and women whereas multi-morbid class 3 had a considerable majority of females and multi-morbid class 4 a considerable majority of males. All characteristics were significantly different across classes (all $p<$ $0.001)$.

\section{Relationship between membership of particular multimorbidity class and participant characteristics}

Multiple logistic regression of assigned membership of each class (vs class 1) identified that individuals were more likely to be classified as "respiratory and atopy" (class 2) than 'healthy' (class 1) if they were female and had family history of asthma (Table 5).

Individuals were more likely to be classified as "multimorbid non-cardio-metabolic" (class 3) than 'healthy' (class 1) if they were female, older, had a larger waist circumference, smoked, and had a family history of asthma, myocardial infarction or cancer.

Individuals were more likely to be classified as "multimorbid cardio-metabolic and other" (class 4) than 'healthy' (class 1) if they were older, had a larger waist circumference, smoked, did less physical activity, and had a family history of asthma, diabetes and myocardial infarction.

These results confirm that predictors of being in classes 2, 3 and 4 differ and are not the same as predictors of the number of conditions.

\section{Discussion}

In this study, we have used an extensive range of clinically measured and self-reported chronic conditions and two complementary analytical approaches to describe the prevalence and patterns of multimorbidity in a community cohort of middle-aged adults. Our first approach, using single disease counts of pairs and triplets of conditions, identified that multimorbidity is prevalent and that 
Table 3 Morbidity characteristics of individuals assigned to Classes of multimorbidity

\begin{tabular}{|c|c|c|c|c|c|}
\hline & $\begin{array}{l}\text { ALL } \\
(\mathrm{N}=5029)\end{array}$ & $\begin{array}{l}\text { CLASS } 1 \\
\text { Relatively } \\
\text { healthy }\end{array}$ & $\begin{array}{l}\text { CLASS } 2 \\
\text { Predominant respiratory } \\
\text { \& atopy }\end{array}$ & $\begin{array}{l}\text { CLASS } 3 \\
\text { Multi-morbid non-cardio- } \\
\text { metabolic }\end{array}$ & $\begin{array}{l}\text { CLASS } 4 \\
\text { Multi-morbid cardio-metabolic } \\
\text { and other }\end{array}$ \\
\hline $\begin{array}{l}\text { Number assigned to } \\
\text { class }\end{array}$ & $\begin{array}{l}5029 \\
(100 \%)\end{array}$ & 3541 (70.4\%) & $529(10.5 \%)$ & 691 (13.7\%) & 268 (5.3\%) \\
\hline $\begin{array}{l}\text { Mean number of } \\
\text { conditions }\end{array}$ & 2.75 & 1.95 & 3.65 & 4.77 & 6.32 \\
\hline Condition & $\begin{array}{l}\text { Prevalence } \\
\text { (\%) }\end{array}$ & $\begin{array}{l}\text { Probability } \\
\text { (\%) }\end{array}$ & $\begin{array}{l}\text { Probability } \\
\text { (\%) }\end{array}$ & $\begin{array}{l}\text { Probability } \\
\text { (\%) }\end{array}$ & $\begin{array}{l}\text { Probability } \\
\text { (\%) }\end{array}$ \\
\hline Atopy & 54.4 & 52.3 & 82.0 & 40.8 & 62.7 \\
\hline Arthritis & 25.1 & 13.3 & 24.6 & 77.1 & 48.1 \\
\hline Bowel disease & 23.3 & 16.5 & 21.9 & 54.1 & 35.4 \\
\hline Liver disease & 23.1 & 21.9 & 23.3 & 15.8 & 57.5 \\
\hline Depression/anxiety & 20.5 & 13.3 & 14.7 & 54.6 & 38.4 \\
\hline Bronchitis & 17.6 & 11.8 & 20.6 & 37.8 & 36.9 \\
\hline Eye condition & 14.6 & 10.8 & 11.9 & 30.4 & 29.1 \\
\hline Asthma & 14.2 & 0.1 & 99.1 & 14.5 & 32.5 \\
\hline Heart disease & 9.7 & 7.7 & 9.1 & 7.4 & 44.0 \\
\hline Thyroid disease & 8.6 & 5.2 & 7.6 & 25.8 & 12.3 \\
\hline Low back pain & 8.5 & 1.6 & 4.7 & 37.5 & 32.5 \\
\hline Skin cancer & 8.2 & 8.7 & 4.7 & 8.7 & 6.3 \\
\hline OSA & 8.1 & 5.8 & 2.5 & 12.4 & 37.3 \\
\hline Hearing impairment & 7.1 & 6.0 & 3.6 & 11.6 & 16.4 \\
\hline Diabetes & 7.0 & 4.2 & 0.0 & 4.3 & 64.6 \\
\hline Non skin cancer & 6.7 & 5.0 & 6.2 & 14.2 & 10.8 \\
\hline COPD & 5.7 & 2.7 & 19.3 & 8.4 & 13.1 \\
\hline Kidney disease & 5.2 & 3.4 & 2.6 & 10.0 & 20.9 \\
\hline Osteoporosis & 3.4 & 2.7 & 4.2 & 7.7 & 0.4 \\
\hline Stroke & 2.1 & 0.9 & 0.8 & 2.5 & 20.1 \\
\hline $\begin{array}{l}\text { Peripheral artery } \\
\text { disease }\end{array}$ & 1.9 & 1.2 & 1.5 & 1.6 & 12.3 \\
\hline
\end{tabular}

some combinations of conditions occur more frequently than expected by chance. Our second approach, using LCA, identified four unbiased classes of multimorbidity, with differences in membership of each class characterised by both higher probability of the number of chronic conditions and a clinically-distinct groupings of conditions. The predictors of chronic disease load (number of conditions) differed from those of patterns of multimorbidity.

Using single disease counts, we showed that, although the majority $(73 \%)$ of adults in this cohort had two or more chronic conditions, the overall prevalence of specific combinations of disease was relatively low. The most prevalent pair (atopy and arthritis) had a prevalence of just over $13 \%$ and the most prevalent triplet (arthritis, bowel disease and atopy) was observed in under $5 \%$ of the cohort. By calculating $\mathrm{O} / \mathrm{E}$ prevalence ratios, we were able to identify combinations of disease that occurred more frequently than expected by chance. Some of the combinations identified in this cohort have obvious pathological links or are well known to co-exist clinically. Asthma and COPD either as a pair, or along with atopy in a triplet, were combinations with high $\mathrm{O} / \mathrm{E}$ ratios and point towards well-documented inflammatory links between allergy and respiratory function. Although we mainly used spirometry to define COPD, the appearance of this condition alongside asthma may point towards overlap of symptoms or diagnostic mislabelling and highlights the need for further research into how these conditions might be better characterised [37].

Arthritis, bowel disease and low back pain were the most common conditions appearing in highest ranked $\mathrm{O} / \mathrm{E}$ combinations alongside depression-anxiety. Arthritis featured in $60 \%$ of the highest-ranking triplets of conditions and bowel disease and depression-anxiety featured in $40 \%$. Depression-anxiety featured in over 
Table 4 Comparison of participant characteristics across assigned multimorbidity classes

\begin{tabular}{|c|c|c|c|c|c|c|}
\hline & ALL & Class 1 & Class 2 & Class 3 & Class 4 & \\
\hline & & $\begin{array}{l}\text { Relatively } \\
\text { healthy }\end{array}$ & $\begin{array}{l}\text { Predominantly } \\
\text { respiratory \& atopy }\end{array}$ & $\begin{array}{l}\text { Multi-morbid non- } \\
\text { cardiometabolic }\end{array}$ & $\begin{array}{l}\text { Multi-morbid } \\
\text { cardiometabolic and } \\
\text { other }\end{array}$ & \\
\hline Characteristic & $\begin{array}{l}(n= \\
5029)\end{array}$ & $(n=3541)$ & $(n=529)$ & $(n=691)$ & $(n=268)$ & $\begin{array}{l}P \text { - } \\
\text { value* }\end{array}$ \\
\hline Age (mean years) & 58.0 & 57.5 & 57.1 & 60.2 & 61.0 & $\begin{array}{l}< \\
0.001\end{array}$ \\
\hline Sex (Female, \%) & 54.8 & 52 & 61 & 73 & 36 & $\begin{array}{l}< \\
0.001\end{array}$ \\
\hline Waist circumference (mean cm) & 92.2 & 91.0 & 90.8 & 93.3 & 108.6 & $\begin{array}{l}< \\
0.001\end{array}$ \\
\hline \multicolumn{7}{|l|}{ Tobacco smoking: } \\
\hline Never (\%) & 47 & 48 & 49 & 43 & 35 & \\
\hline Former (\%) & 43 & 43 & 43 & 41 & 51 & \\
\hline Current < 15 cigarettes per day (\%) & 4 & 4 & 3 & 7 & 4 & $\begin{array}{l}< \\
0.001\end{array}$ \\
\hline Current 15 cigarettes per day (\%) & 6 & 5 & 5 & 9 & 9 & \\
\hline $\begin{array}{l}\text { Moderate/vigorous physical activity } \\
\text { (mean total hours per week) }\end{array}$ & 9.5 & 10.1 & 9.0 & 7.8 & 7.4 & $\begin{array}{l}< \\
0.001\end{array}$ \\
\hline $\begin{array}{l}\text { Alcohol consumption (mean total } \\
\text { glasses per week) }\end{array}$ & 11.5 & 11.9 & 10.9 & 9.7 & 12.1 & 0.001 \\
\hline \multicolumn{7}{|l|}{ First degree relatives ${ }^{\#}$ with: } \\
\hline Asthma & 0.34 & 0.29 & 0.59 & 0.37 & 0.39 & $\begin{array}{l}< \\
0.001\end{array}$ \\
\hline Diabetes & 0.37 & 0.34 & 0.36 & 0.42 & 0.61 & $\begin{array}{l}< \\
0.001\end{array}$ \\
\hline Myocardial infarct & 0.5 & 0.47 & 0.44 & 0.62 & 0.69 & $\begin{array}{l}< \\
0.001\end{array}$ \\
\hline Cancer (any type) & 0.86 & 0.82 & 0.84 & 1.03 & 0.91 & $\begin{array}{l}< \\
0.001\end{array}$ \\
\hline
\end{tabular}

* P-value from chi-square test for categorical characteristic or from ANOVA for quantitative characteristic

\# Condition reported in biological mother, father, brother(s), sister(s) - mean number

one-third of all triplets identified and was highly prevalent among LCA Class 4 with the highest condition load. Depression is a common feature of multimorbidity [38] and has been associated with a range of chronic conditions including cardiac disease, stroke, loss of hearing, loss of vision, and chronic lung diseases such as asthma and COPD [39, 40]. In our study, depression-anxiety often featured in combination with arthritis, back pain and bowel disease. Previous studies have shown high prevalence of depression and anxiety in inflammatory bowel disorders such as ulcerative colitis and Crohn's disease $[41,42]$. Depression is also a common comorbid feature in different arthritis subtypes [43] and can worsen both the severity of and disability caused by chronic low back pain [44]. As depression is a treatable illness, a rational approach may be to screen for and treat comorbid depression in patients presenting with these patterns of multimorbidity.

Other combinations of disease identified in our study may point towards shared aetiologies. The high co- occurrence of arthritis with bowel disease has been described in previous studies and was a common combination identified in both our disease counts (7/27 triplets) and occurred in high prevalence in LCA Classes 3 and 4 $[45,46]$. Previous studies have suggested changes in gut bacteria as potentially implicated in the development of joint inflammation, or alternatively recruitment of gut lymphocytes or activated macrophages in joint inflammation [47].

Common risk factors such as obesity, tobacco smoking, physical inactivity, and family history may underlie some of these patterns, yet predictors of latent class membership showed distinct differences. Our analysis of the lifestyle factors underlying class membership or the number of chronic conditions did not find alcohol consumption or diet variables (data not shown) to be significant variables.

\section{LCA patterns}

The largest disease burden was evident in Classes 3 and 4 , which together comprised around $20 \%$ of the cohort. 
Table 5 Relationship between membership of particular multi-morbidity class and participant characteristics

\begin{tabular}{|c|c|c|c|c|c|c|}
\hline \multirow{2}{*}{$\begin{array}{l}\text { Comparison } \\
\text { Characteristic }\end{array}$} & \multicolumn{2}{|l|}{ Class 2 vs Class 1} & \multicolumn{2}{|l|}{ Class 3 vs Class 1} & \multicolumn{2}{|l|}{ Class 4 vs Class 1} \\
\hline & Estimated odds ratio & $P$ Value & Estimated odds ratio & $P$ Value & Estimated odds ratio & P Value \\
\hline Sex (female vs male) & 1.409 & 0.0023 & 3.227 & $<0.0001$ & 1.076 & 0.6511 \\
\hline Age (per year) & 0.996 & 0.6518 & 1.089 & $<0.0001$ & 1.113 & $<0.0001$ \\
\hline Waist circumference (per cm) & 1.006 & 0.1275 & 1.026 & $<0.0001$ & 1.097 & $<0.0001$ \\
\hline \multicolumn{7}{|l|}{ Tobacco smoking } \\
\hline Current 15 cigs/day vs never & 0.982 & 0.9370 & 3.382 & $<0.0001$ & 3.216 & $<0.0001$ \\
\hline Current $<15$ cigs/day vs never & 0.816 & 0.4383 & 2.527 & $<0.0001$ & 1.915 & 0.0737 \\
\hline Former smoker vs Never smoked & 0.959 & 0.6769 & 1.084 & 0.3951 & 1.228 & 0.1869 \\
\hline $\begin{array}{l}\text { Weekly moderate/vigorous physical } \\
\text { activity (per hr) }\end{array}$ & 0.995 & 0.2739 & 0.993 & 0.0703 & 0.986 & 0.0251 \\
\hline \multicolumn{7}{|l|}{ First degree relative with: } \\
\hline Asthma & 1.834 & $<.0001$ & 1.189 & 0.0139 & 1.335 & 0.0080 \\
\hline Diabetes & 0.981 & 0.8029 & 1.076 & 0.2792 & 1.437 & 0.0001 \\
\hline Myocardial infarct & 0.882 & 0955 & 1.141 & 0.0293 & 1.291 & 0.0065 \\
\hline Cancer (any) & 0.999 & 0.9790 & 1.237 & $<0.0001$ & 1.061 & 0.4747 \\
\hline
\end{tabular}

Individuals assigned to Class 3 multi-morbid noncardiometabolic had an average of over 4 chronic conditions and showed a higher probability of musculoskeletal conditions (arthritis, low back pain and osteoporosis); conditions resulting in sensory deficits (hearing impairment and eye conditions); and non-cardiovascular conditions including bowel, thyroid and kidney diseases. Individuals in this category were more likely to be female $(73 \%)$ and older than those in classes 1 and 2 . While only $5 \%$ of the cohort was assigned to Class 4 , this class was $64 \%$ male and had the highest disease load with an average of six co-occurring chronic conditions. Cardiometabolic conditions including heart disease, diabetes, stroke, and peripheral artery disease along with liver disease and sleep apnoea were highly prevalent in this group. Individuals in Class 4 were much more likely to be male, older and obese.

Similar to the findings for common pairs and triplets, Class 2 was characterised by above-average prevalence of respiratory and allergy conditions but did not significantly differ from Class 1 (relatively healthy) in terms of age, obesity or smoking status. This is interesting because this class shows a distinct clustering of multimorbidity that was not associated with increased age (the average age was lower in this group compared with Classes 3 and 4) or with behavioural risk factors related to poor lung function, such as smoking and excess abdominal fat (compared with Class 1). Family history of asthma was a significant predictor of membership of this group, perhaps highlighting a strong genetic and early life component underlying this pattern of multimorbidity.
Comparing our findings with previous studies that identify multimorbidity patterns is difficult due to the heterogeneity in the populations and age-ranges sampled, disease type and number of conditions included, as well as variation in data sources and analytical methods. Nonetheless a systematic review of 14 studies on nonrandom patterns of multimorbidity provides support for three broad categories consisting of cardiovascular and metabolic diseases, musculoskeletal disorders and mental health disorders [27]. Using disease counts, similar patterns have been described in Australian samples. Britt et al. found that arthritis, chronic back pain and depression-anxiety conditions were the most prevalent combinations of conditions, along with vascular disease, in older primary-care patients [20]. Holden et al. used exploratory factor analysis to describe patterns and identified a dominant group with arthritis and irritable bowel disease [17].

Relatively few published studies have employed LCA to describe multimorbidity classes in general population samples. An Australian study of over 4500 adults with mean age of 69 years included 11 self-reported disease conditions resulting in four multimorbidity LCA classes [18]. Similar to our findings, the majority of the study sample $(>55 \%)$ were assigned to a minimally diseased ('healthy') group. The remainder were assigned to groups characterised by dominant presence of either: arthritis and asthma and depression-anxiety; high blood pressure and diabetes, or; cancer and heart disease and stroke. The clustering of conditions in that study was largely consistent across the multiple analytical techniques employed, which included pair/triplet disease 
combinations and cluster analyses. While we identified broadly similar combinations of conditions and clusters in our study sample, it is likely that inclusion of more conditions in our analyses resulted in a distinct grouping of cardio-metabolic conditions that included diabetes, heart disease and stroke into a single class (Class 4). A study using 15 self-reported conditions in over 160,000 Danish citizens with mean age 47 years, identified seven classes of multimorbidity, three of which were similar to those identified in our analyses [21]. These include a distinct "musculoskeletal class" characterised by high probability of arthritis, osteoporosis and back injuries; a "complex cardio-metabolic disorders" class with high probability of diabetes, heart disease and stroke, similar to our Class 4; and a third class termed "asthma-allergy", similar to our Class 2 but which did not include COPD.

A US study of over 14,000 adults aged over 65 years used 13 self-reported conditions identified six latent multimorbidity classes [36]. Only one-third were assigned to a "Minimal disease" group and the remainder spread between groups characterised by vascular, non-vascular, cardio-stroke-cancer or neurological disease, and a 'Very sick' group with above average prevalence of all conditions. These findings differ from our study in that we found distinct differences between predictors of class membership and number of diseases, and that the majority of our sample (70\%) fell within a relatively healthy (minimal disease) group, the latter of which may be explained by the overall younger age of our cohort.

Comparing the patterns of multimorbidity identified in our study and others conducted in high income countries, with patterns identified in low-middle income countries is difficult given the different nature of disease burden and the limited availability of studies. Nonetheless a recent LCA analysis in cohorts from both low and high income countries identified three classes, two of which labelled "cardio-metabolic" and "healthy" were similar to those found in our study and others [27, 48]. However the proportion of individuals in each of the multimorbidity classes differed across regions highlighting the difficulties in comparing multimorbidity burden and patterns across different socio-economic and epidemiological settings.

\section{Strengths}

The strengths of our study include a high participation and completion rate in a moderately large communitydwelling cohort, assessed at an age where chronic disease load often begins to manifest. By using a large number of conditions (over $50 \%$ of which were defined by physical or biochemical clinical measure or validated instrument score) and including those conditions that are current and chronic (long-lasting symptoms and likely to impact on daily activities) we have captured a comprehensive range of conditions of ageing that have not been able to be included in previous studies of multimorbidity.

\section{Limitations}

Our sample was drawn from a regional urban community; however the cohort was similar on a number of key health indicators to the general Australian population. Current medication use, although available, was not included in the definition or criteria for any of the conditions so as to avoid potential misclassification errors that may arise from off-label prescribing or under-reporting. Without an objective clinical marker for arthritis (similar to other studies), we have relied on self-reported doctor diagnosis, but we used validated instrument scores to capture musculoskeletal conditions including low back pain and a wide range of gastrointestinal disorders in our definition of bowel disease, some of which have not often been included in previous studies of multimorbidity patterns [32].

When defining multimorbidity, "health conditions" may include diseases, risk factors or symptoms. The present analysis has included predominantly conditions that are diseases or symptoms. We therefore did not include conditions such as obesity or hypertension. While hypertension can be considered a cardiovascular condition, it was not included in this analysis because of its very strong risk factor association with stroke, heart disease, kidney disease and diabetes and is thus a somewhat redundant aspect of the cardio-metabolic profile and patterns identified. Decisions on what to include when defining multimorbidity depend on the purpose of the definition, e.g. assessing effects on perceived future risk, or effects on current function and disability, or effects on health care costs [48]. The present study aimed at examining how diseases and symptoms co-occurred and might be predicted.

\section{Conclusion}

Our findings indicate that multimorbidity is common among middle-aged adults and some conditions cooccur in clinically distinct patterns and at higher prevalence than expected by chance. The identification of non-random patterns of multimorbidity may guide further mechanistic studies into shared biological and environmental causes of co-occurring conditions of ageing. As the Busselton Healthy Ageing Study is designed as a longitudinal survey, the conduct of future phases and analyses will track and relate patterns of multimorbidity to prevalent and incident cognitive and physical disability and use of healthcare resources. The findings of these 
studies will be of major importance to the primary rather than specialist care management of older individuals in whom multiple physical and mental health conditions require a holistic view.

\section{Abbreviations}

AP: Anterior-posterior; ABI: Ankle-Brachial Index; AIC: Akaike Information Criterion; ALT: Alanine transferase; ANOVA: Analysis of variance; BHAS: Busselton Healthy Ageing Study; BIC: Bayesian Information Criterion; $\mathrm{cm}$ : centimetre; COPD: Chronic obstructive pulmonary disease; $\mathrm{dB}$ : decibels; DXA: Dual energy $x$-ray absorptiometry; ECG: electrocardiogram; FEV1: Forced expired volume in $1 \mathrm{~s}$; FVC: Forced vital capacity; GAD7: Generalised anxiety disorder - 7 item scale; HbA1c: glycated haemoglobin; Hz: Hertz; LCA: Latent Class Analysis; $\mathrm{ml} / \mathrm{min}$ : millilitres per minute; $\mathrm{mm}$ : millimetre; mmol/ L: millimoles per litre; O/E: Observed/expected; PHQ9: Patient Health Questionnaire-9; SD: Standard deviation; TIA: Transient ischemic attack; U/ L: Units per litre

\section{Supplementary Information}

The online version contains supplementary material available at https://doi. org/10.1186/s12889-021-11578-y.

Additional file 1. Supplementary File 1. BHAS Phase 1 Questionnaire 2010-2015.

Additional file 2. Supplementary File 2. Statistical Supplement. Latent Class Analysis method.

Additional file 3. Supplementary Table S1. Mean, median and maximum number of conditions by gender and demographic groups.

Additional file 4. Supplementary Table S2. Relationship between number of conditions and participant characteristics.

Additional file 5 Supplementary Table S3. All triplets of conditions with prevalence $>1.5 \%$ and observed/expected (O/E) ratio $>1.5$ (and $p$ value< 0.0001).

Additional file 6. Supplementary Table S4. Morbidity patterns and number of conditions. Number of participants with each number of conditions and percentage within each morbidity pattern.

\section{Acknowledgements}

The Busselton Healthy Ageing Study is supported by grants from the Government of Western Australia (Department of Jobs, Tourism, Science and Innovation), the Commonwealth Government (Department of Health), the City of Busselton and from private donations to the Busselton Population Medical Research Institute. Assays and consumables used in the baseline survey and assessments were generously provided by Pathwest, Stallergenes, Resmed and BD Biosciences. The authors wish to thank Mark Divitini and Kashif Mukhtar and the BPMRI Busselton Health Study Centre staff and volunteers for survey operations. We thank the Western Australian Country Health Service for infrastructure support, and the BPMRI Community Advisory Committee and the people of Busselton for their participation.

\section{Authors' contributions}

$M H, M K, B M, J H, K M, J B, D H, J H, R N, R B, L S, J W, K Z, D B, R E, T D, D M \& A J$ contributed to the study conception, design and interpretation of data. Data acquisition, preparation and analysis were performed by $\mathrm{MH}, \mathrm{KM}$ and $\mathrm{MK}$, respectively. The first draft of the manuscript was written by $\mathrm{MH}, \mathrm{MK}$ and $\mathrm{AJ}$ and all authors commented on previous versions of the manuscript. All authors read and approved the final manuscript.

\section{Funding}

Data collection and research assistant salary costs in the Busselton Healthy Ageing Study were supported by grants from the Government of Western Australia (Department of Jobs, Tourism, Science and Innovation), the Commonwealth Government (Department of Health), the City of Busselton and from private donations to the Busselton Population Medical Research Institute. The funders had no role in study design, data collection and analysis, decision to publish or preparation of the manuscript.

\section{Availability of data and materials}

Data is available by application to the Busselton Population Medical Research Institute.

\section{Declarations}

Ethics approval and consent to participate

Ethical approval for this study was obtained from the Human Research Ethics Committee of the University of Western Australia (RA/4/1/2203). The study was performed in accordance with the ethical standards as laid down in the 1964 Declaration of Helsinki. Written informed consent was obtained from all individual participants included in the study.

\section{Consent for publication}

Not Applicable.

\section{Competing interests}

The authors have no competing interests to declare that are relevant to the content of this article.

\section{Author details}

${ }^{1}$ Busselton Population Medical Research Institute Inc, Nedlands, WA 6009, Australia. ${ }^{2}$ School of Population and Global Health, The University of Western Australia, Crawley, WA 6009, Australia. ${ }^{3}$ BPMRI Busselton Health Study Centre, PO Box 659, Busselton, Western Australia 6280. ${ }^{4}$ PathWest Laboratory Medicine of WA, QEII Medical Centre, Nedlands, WA 6009, Australia. ${ }^{5}$ Department of Pulmonary Physiology and Sleep Medicine, Sir Charles Gairdner Hospital, Nedlands, WA 6009, Australia. ${ }^{6}$ Faculty of Health and Medical Sciences, Medical School, University of Western Australia, Crawley 6009, Australia. 'Exercise Medicine Research Institute, Edith Cowan University, Joondalup, WA 6027, Australia. ${ }^{8}$ School of Psychological Science, University of Western Australia, Perth, WA 6083, Australia. ${ }^{9}$ School of Physiotherapy and Exercise Science, Curtin University, Bentley, WA 6845, Australia. ${ }^{10}$ Department of Endocrinology and Diabetes, Sir Charles Gairdner Hospital, Nedlands, WA 6009, Australia. "1'Ear Science Institute Australia, Subiaco, WA 6008, Australia.

${ }^{12}$ Ear Sciences Centre, The University of Western Australia, Crawley, WA, Australia. ${ }^{13}$ Department of Speech Language Pathology and Audiology, University of Pretoria, Pretoria, South Africa. ${ }^{14}$ Medical School, University of Western Australia, Fremantle Hospital, Fremantle, WA 6959, Australia.

${ }^{15}$ Centre for Ophthalmology and Visual Science, University of Western Australia, Lions Eye Institute, Perth, Australia.

Received: 27 January 2021 Accepted: 30 July 2021

Published online: 11 August 2021

\section{References}

1. Johnston MC, Crilly M, Black C, Prescott GJ, Mercer SW. Defining and measuring multimorbidity: a systematic review of systematic reviews. Eur J Pub Health. 2019;29(1):182-9. https://doi.org/10.1093/eurpub/cky098.

2. Chandraratne NK, Pathirathna K, Harrison C, Siriwardena AN. A comparison of policies and guidelines related to multimorbidity in the UK, Australia and Sri Lanka. Aust J Gen Pract. 2018;47(1-2):14-9. https://doi.org/10.31128/AFP09-17-4346.

3. Nunes BP, Flores TR, Mielke GI, Thume E, Facchini LA. Multimorbidity and mortality in older adults: a systematic review and meta-analysis. Arch Gerontol Geriatr. 2016;67:130-8. https://doi.org/10.1016/j.archger.2016.07.008.

4. Fortin M, Bravo G, Hudon C, Lapointe L, Almirall J, Dubois MF, et al. Relationship between multimorbidity and health-related quality of life of patients in primary care. Qual Life Res. 2006;15(1):83-91. https://doi.org/10.1 007/s11136-005-8661-z.

5. Barnett K, Mercer SW, Norbury M, Watt G, Wyke S, Guthrie B. Epidemiology of multimorbidity and implications for health care, research, and medical education: a cross-sectional study. Lancet. 2012;380(9836):37-43. https://doi. org/10.1016/50140-6736(12)60240-2.

6. Fortin M, Bravo G, Hudon C, Lapointe L, Dubois MF, Almirall J. Psychological distress and multimorbidity in primary care. Ann Fam Med. 2006:4(5):41722. https://doi.org/10.1370/afm.528.

7. Fabbri E, An Y, Zoli M, Tanaka T, Simonsick EM, Kitner-Triolo MH, et al. Association between accelerated multimorbidity and age-related cognitive decline in older Baltimore longitudinal study of aging participants without 
dementia. J Am Geriatr Soc. 2016;64(5):965-72. https://doi.org/10.1111/jgs.14 092.

8. Sheridan PE, Mair CA, Quinones AR. Associations between prevalent multimorbidity combinations and prospective disability and self-rated health among older adults in Europe. BMC Geriatr. 2019;19(1):198. https:// doi.org/10.1186/s12877-019-1214-z.

9. Vogel I, Miksch A, Goetz K, Ose D, Szecsenyi J, Freund T. The impact of perceived social support and sense of coherence on health-related quality of life in multimorbid primary care patients. Chronic IIIn. 2012;8(4):296-307. https://doi.org/10.1177/1742395312445935.

10. Troelstra SA, Straker L, Harris M, Brown S, van der Beek AJ, Coenen P. Multimorbidity is common among young workers and related to increased work absenteeism and presenteeism: results from the population-based Raine study cohort. Scand J Work Environ Health. 2020;46(2):218-27. https:// doi.org/10.5271/sjweh.3858.

11. Abebe F, Schneider M, Asrat B, Ambaw F. Multimorbidity of chronic noncommunicable diseases in low- and middle-income countries: A scoping review. J Comorb. 2020;10:2235042X20961919.

12. Muth C, Blom JW, Smith SM, Johnell K, Gonzalez-Gonzalez Al, Nguyen TS, et al. Evidence supporting the best clinical management of patients with multimorbidity and polypharmacy: a systematic guideline review and expert consensus. J Intern Med. 2019;285(3):272-88. https://doi.org/10.1111/joim.12 842.

13. Kernick D, Chew-Graham CA, O'Flynn N. Clinical assessment and management of multimorbidity: NICE guideline. Br J Gen Pract. 2017; 67(658):235-6. https://doi.org/10.3399/bjgp17X690857.

14. National Institute for Health and Care Excellence. Multimorbidity: clinical assessment and management. NICE guideline [NG56]. 2016. https://www. nice.org.uk/guidance/ng56. Accessed 10 July 2020.

15. Nadeeka KC, Pathirathna K, Christopher H, Siriwardena AN. A comparison of policies and guidelines. Austr J Gen Pract. 2018;47(1-2):14-9.

16. Fortin M, Stewart M, Poitras ME, Almirall J, Maddocks H. A systematic review of prevalence studies on multimorbidity: toward a more uniform methodology. Ann Fam Med. 2012;10(2):142-51. https://doi.org/10.1370/a fm.1337.

17. Holden L, Scuffham PA, Hilton MF, Muspratt A, Ng SK, Whiteford HA Patterns of multimorbidity in working Australians. Popul Health Metrics. 2011:9(1):15. https://doi.org/10.1186/1478-7954-9-15.

18. Islam MM, Valderas JM, Yen L, Dawda P, Jowsey T, McRae IS. Multimorbidity and comorbidity of chronic diseases among the senior Australians: prevalence and patterns. PLoS One. 2014;9(1):e83783. https://doi.org/10.13 71/journal.pone.0083783.

19. Walker AE. Multiple chronic diseases and quality of life: patterns emerging from a large national sample, Australia. Chronic IIIn. 2007;3(3):202-18. https://doi.org/10.1177/1742395307081504.

20. Britt HC, Harrison CM, Miller GC, Knox SA. Prevalence and patterns of multimorbidity in Australia. Med J Aust. 2008;189(2):72-7. https://doi.org/10. 5694/j.1326-5377.2008.tb01919.x.

21. Larsen FB, Pedersen MH, Friis K, Glümer C, Lasgaard M. A Latent Class Analysis of Multimorbidity and the Relationship to Socio-Demographic Factors and Health-Related Quality of Life. A National Population-Based Study of 162,283 Danish Adults. PLoS One. 2017;12(1):e0169426.

22. Diederichs C, Berger K, Bartels DB. The measurement of multiple chronic diseases--a systematic review on existing multimorbidity indices. J Gerontol A Biol Sci Med Sci. 2011;66(3):301-11.

23. Huntley AL, Johnson R, Purdy S, Valderas JM, Salisbury C. Measures of multimorbidity and morbidity burden for use in primary care and community settings: a systematic review and guide. Ann Fam Med. 2012; 10(2):134-41. https://doi.org/10.1370/afm.1363.

24. Nicholson K, Almirall J, Fortin M. The measurement of multimorbidity. Health Psychol. 2019;38(9):783-90. https://doi.org/10.1037/hea0000739.

25. Fortin M, Haggerty J, Sanche S, Almirall J. Self-reported versus health administrative data: implications for assessing chronic illness burden in populations. A cross-sectional study. CMAJ Open. 2017:5(3):E729-E33. https://doi.org/10.9778/cmajo.20170029.

26. Lujic S, Simpson JM, Zwar N, Hosseinzadeh H, Jorm L. Multimorbidity in Australia: comparing estimates derived using administrative data sources and survey data. PLoS One. 2017;12(8):e0183817. https://doi.org/10.1371/ journal.pone.0183817.
27. Prados-Torres A, Calderón-Larrañaga A, Hancco-Saavedra J, Poblador-Plou B, van den Akker M. Multimorbidity patterns: a systematic review. J Clin Epidemiol. 2014;67(3):254-66. https://doi.org/10.1016/j.jclinepi.2013.09.021.

28. Bastian LA, Brandt CA, Justice AC. Measuring multimorbidity: a risky business. J Gen Intern Med. 2017;32(9):959-60. https://doi.org/10.1007/s11 606-017-4110-2.

29. James A, Hunter M, Straker L, Beilby J, Bucks R, Davis T, et al. Rationale, design and methods for a community-based study of clustering and cumulative effects of chronic disease processes and their effects on ageing: the Busselton healthy ageing study. BMC Public Health. 2013;13(1):936. https://doi.org/10.1186/1471-2458-13-936.

30. Levey AS, Stevens LA, Schmid CH, Zhang YL, Castro AF 3rd, Feldman HI, et al. A new equation to estimate glomerular filtration rate. Ann Intern Med. 2009;150(9):604-12. https://doi.org/10.7326/0003-4819-150-9-200905050 00006.

31. Craig CL, Marshall AL, Sjostrom M, Bauman AE, Booth ML, Ainsworth BE, et al. International physical activity questionnaire: 12-country reliability and validity. Med Sci Sports Exerc. 2003;35(8):1381-95. https://doi.org/10.1249/01. MSS.0000078924.61453.FB.

32. Fairbank JC, Pynsent PB. The Oswestry disability index. Spine (Phila Pa 1976). 2000;25(22):2940-52; discussion 52. https://doi.org/10.1097/00007632-2 00011150-00017.

33. Kroenke K, Spitzer RL, Williams JB. The PHQ-9: validity of a brief depression severity measure. J Gen Intern Med. 2001;16(9):606-13. https://doi.org/10.1 046/j.1525-1497.2001.016009606.x

34. Spitzer RL, Kroenke K, Williams JB, Lowe B. A brief measure for assessing generalized anxiety disorder: the GAD-7. Arch Intern Med. 2006;166(10): 1092-7. https://doi.org/10.1001/archinte.166.10.1092.

35. Harrison C, Henderson J, Miller G, Britt H. The prevalence of complex multimorbidity in Australia. Aust N Z J Public Health. 2016:40(3):239-44. https://doi.org/10.1111/1753-6405.12509.

36. Whitson HE, Johnson KS, Sloane $R$, Cigolle CT, Pieper CF, Landerman $L$, et al. Identifying patterns of multimorbidity in older Americans: application of latent class analysis. J Am Geriatr Soc. 2016;64(8):1668-73. https://doi.org/1 $0.1111 /$ jgs.14201.

37. James AL, Knuiman MW, Divitini ML, Hui J, Hunter M, Palmer LJ, et al. Changes in the prevalence of asthma in adults since 1966: the Busselton health study. Eur Respir J. 2010;35(2):273-8. https://doi.org/10.1183/0903193 6.00194308

38. Read JR, Sharpe L, Modini M, Dear BF. Multimorbidity and depression: a systematic review and meta-analysis. J Affect Disord. 2017;221:36-46. https://doi.org/10.1016/j.jad.2017.06.009.

39. Stanton R, Rosenbaum S, Rebar A, Happell B. Prevalence of chronic health conditions in Australian adults with depression and/or anxiety. Iss Ment Health Nurs. 2019:40(10):902-7. https://doi.org/10.1080/01612840.2019.1613701.

40. Huang CQ, Dong BR, Lu ZC, Yue JR, Liu QX. Chronic diseases and risk for depression in old age: a meta-analysis of published literature. Ageing Res Rev. 2010;9(2):131-41. https://doi.org/10.1016/j.arr.2009.05.005.

41. Mikocka-Walus A, Knowles SR, Keefer L, Graff L. Controversies revisited: a systematic review of the comorbidity of depression and anxiety with inflammatory bowel diseases. Inflamm Bowel Dis. 2016;22(3):752-62. https:// doi.org/10.1097/MIB.0000000000000620.

42. Neuendorf R, Harding A, Stello N, Hanes D, Wahbeh H. Depression and anxiety in patients with inflammatory bowel disease: a systematic review. J Psychosom Res. 2016;87:70-80. https://doi.org/10.1016/j.jpsychores.2016.06.001.

43. Brooks JM, Titus AJ, Polenick CA, Orzechowski NM, Reid MC, MacKenzie TA, et al. Prevalence rates of arthritis among US older adults with varying degrees of depression: findings from the 2011 to 2014 National Health and nutrition examination survey. Int J Geriatr Psychiatry. 2018;33(12):1671-9. https://doi.org/10.1002/gps.4971.

44. Carley JA, Karp JF, Gentili A, Marcum ZA, Reid MC, Rodriguez E, et al. Deconstructing chronic low Back pain in the older adult: step by step evidence and expert-based recommendations for evaluation and treatment: part IV: depression. Pain Med. 2015;16(11):2098-108. https://doi.org/10.1111/ pme.12935

45. Karreman MC, Luime JJ, Hazes JMW, Weel A. The prevalence and incidence of axial and peripheral Spondyloarthritis in inflammatory bowel disease: a systematic review and Meta-analysis. J Crohns Colitis. 2017:11(5):631-42. https://doi.org/10.1093/ecco-jcc/jjw199. 
46. Brakenhoff LK, van der Heijde DM, Hommes DW, Huizinga TW, Fidder HH. The joint-gut axis in inflammatory bowel diseases. J Crohns Colitis. 2010;4(3): 257-68. https://doi.org/10.1016/j.crohns.2009.11.005.

47. Speca S, Dubuquoy L. Chronic bowel inflammation and inflammatory joint disease: pathophysiology. Joint Bone Spine. 2017;84(4):417-20. https://doi. org/10.1016/j.jbspin.2016.12.016.

48. Willadsen TG, Bebe A, Koster-Rasmussen R, Jarbol DE, Guassora AD, Waldorff $F B$, et al. The role of diseases, risk factors and symptoms in the definition of multimorbidity - a systematic review. Scand J Prim Health Care. 2016;34(2): 112-21. https://doi.org/10.3109/02813432.2016.1153242.

\section{Publisher's Note}

Springer Nature remains neutral with regard to jurisdictional claims in published maps and institutional affiliations.

- fast, convenient online submission

- thorough peer review by experienced researchers in your field

- rapid publication on acceptance

- support for research data, including large and complex data types

- gold Open Access which fosters wider collaboration and increased citations

- maximum visibility for your research: over $100 \mathrm{M}$ website views per year

At $\mathrm{BMC}$, research is always in progress. 